\title{
A reversal of climatic trends in the North Atlantic since 2005
}

Article

Accepted Version

Robson, J., Ortega, P. and Sutton, R. (2016) A reversal of climatic trends in the North Atlantic since 2005. Nature Geoscience, 9 (7). pp. 513-517. ISSN 1752-0894 doi: https://doi.org/10.1038/ngeo2727 Available at https://centaur.reading.ac.uk/65519/

It is advisable to refer to the publisher's version if you intend to cite from the work. See Guidance on citing.

To link to this article DOI: http://dx.doi.org/10.1038/ngeo2727

Publisher: Nature Publishing Group

All outputs in CentAUR are protected by Intellectual Property Rights law, including copyright law. Copyright and IPR is retained by the creators or other copyright holders. Terms and conditions for use of this material are defined in the End User Agreement.

\section{www.reading.ac.uk/centaur}

\section{CentAUR}

Central Archive at the University of Reading

Reading's research outputs online 


\author{
Jon Robson* Pablo Ortega, Rowan Sutton \\ NCAS-Climate, Department of Meteorology, University of Reading
}

April 20, 2016

5 In the mid-1990s the North Atlantic subpolar gyre warmed rapidly (1), which

6 had important climate impacts, such as increased hurricane numbers (2), 7 and changes to rainfall over Africa, Europe and North America $(3 ; 4)$. Ev8 idence suggests that the warming was largely due to a strengthening of the 9 ocean circulation, particularly the Atlantic Meridional Overturning Circuto lation (AMOC) $(1 ; 5 ; 6 ; 7)$. Since the mid-1990s direct and indirect mea1 surements have suggested a decline in the strength of the ocean circulation $12(8 ; 9)$, which is expected to lead to a reduction in northward heat trans13 port $(10 ; 11)$. Here we show that since 2005 a large volume of the upper 14 North Atlantic Ocean has cooled significantly by approximately $-0.45{ }^{\circ} \mathrm{C}$ or ${ }_{15}-1.5 \times 10^{22} \mathrm{~J}$, reversing the previous warming trend. By analysing observations 16 and a state-of-the-art climate model, we show that this cooling is consistent 17 with a reduction in the strength of the ocean circulation and heat transport, ${ }_{18}$ linked to record low densities in the deep Labrador Sea (9). The low density 19 in the deep Labrador Sea is primarily due to deep ocean warming since 1995, 20 but a long-term freshening also played a role. The observed upper ocean cooling since 2005 is not consistent with the hypothesis that anthropogenic aerosols directly drive Atlantic temperatures (12).

${ }^{*}$ Corresponding author 
Over the past 100 or so years the North Atlantic has experienced substantial multidecadal changes in temperature (4), which have been linked to important climate impacts $(2 ; 4 ; 3)$. It is widely hypothesised that changes in strength of the ocean circulation, and related heat transports, have been important for driving these changes in temperature $(1 ; 5 ; 10 ; 11 ; 13 ; 14)$. However, the relative role of ocean circulation compared to other factors, such as anthropogenic aerosol forcing or surface flux changes, is still questioned $(12 ; 15)$. Observations, direct and indirect, now suggest that the strength of the AMOC has declined recently $(8 ; 9)$, and some studies have suggested a large-scale cooling of the North Atlantic should be expected over the current decade $(11 ; 14 ; 16)$. Such a cooling would be a major contrast to the rapid warming that occurred in the 1990s. In this study we investigate recent changes in the North Atlantic Ocean state, and we use climate model simulations to interpret the processes involved.

Figures 1 and 2 show recent trends in the North Atlantic Ocean and atmosphere: Over the period 1990-2004 the upper ocean (0-700m) warmed significantly, particularly the subpolar gyre $\left(\mathrm{SPG} ; 60-10^{\circ} \mathrm{W}, 50-65^{\circ} \mathrm{N}\right)$, and it also became more salty (figure $1 \mathrm{a}-\mathrm{c}$ ), consistent with an increase in the AMOC and related heat and salt transports (10). Sea Surface Temperature (SST) warmed across the whole North Atlantic, including in the subtropical gyre. In the atmosphere, there was a trend towards a negative North Atlantic Oscillation (NAO (17)) pattern and a reduction in the strength of the westerlies and surface heat loss over the SPG (figure $2 \mathrm{a}$ and c). There was also a decrease in windstress curl (and hence in Ekman upwelling) in the northeast SPG and northeast of Iceland, but an increase in the southeast SPG (figure $2 \mathrm{~b}$ ). The atmospheric trends in figure $2 \mathrm{a}-\mathrm{c}$ are therefore consistent with some contribution from reduced surface heat flux (SHF) cooling and Ekman upwelling to the warming over the period 1990-2004 (1). However, previous modelling experiments indicate that the warming, particularly in the eastern SPG $\left(35-10^{\circ} \mathrm{W}\right)$, was dominated by a strengthening of the AMOC and related ocean heat transport $(1 ; 5 ; 6)$.

Over the period 2005-2014 a substantial cooling and freshening of the upper ocean in the North East Atlantic $\left(50-10^{\circ} \mathrm{W}, 35-65^{\circ} \mathrm{N}\right)$ is evident (Figure $\left.1 \mathrm{~d}-\mathrm{f}\right)$. A significant cooling of SST is also observed centred on $\sim 50^{\circ} \mathrm{N}$ (fig. 1d). Along the western boundary south of Newfoundland a large warming and salinification trend is seen. The SST cooling 
54

trend exhibits some sensitivity to the end-points of the trend analysis, but the heat and salinity content trends are not sensitive (figure S1). Therefore, we have confidence that the observed upper ocean cooling is a decadal time-scale change.

In the atmosphere, the 2005-2014 period shows a trend to lower pressure over the Eastern SPG (figure $2 \mathrm{~d}$ ), and an increase in heat loss from the Labrador Sea and along the western boundary is also observed (see figure $2 \mathrm{f}$ ). The trends in windstress curl imply increased Ekman upwelling in the northeast SPG (see figure $2 \mathrm{e}$ ). Although the changes in surface fluxes and Ekman upwelling would both contribute a cooling, the spatial pattern of cool anomalies is more extensive and quite different (compare figures $1 \mathrm{e}$ and $2 \mathrm{e}$ and f). Additionally, the trend in SLP is sensitive to the inclusion of winter 2013/2014 (see supplementary figure S1), whereas the heat content trends are not (i.e. suggesting that SLP trends are not responsible for the cooling). Further, a quantitative estimate of the anomalous heat budget also suggests that SHFs and Ekman upwelling cannot account for the observed cooling (see supplementary figure S2). Taken together, the evidence suggests that the observed cooling of a large region of the upper North Atlantic Ocean since 2005 cannot be explained as a direct response to changes in atmospheric circulation over the same period.

The simultaneous cooling and freshening of the upper ocean is, however, consistent with a reduction in ocean circulation impacting on both northward heat and salt transport (e.g. (10)). Furthermore, the concurrent increases in heat and salt content seen along the western boundary are also consistent with a declining AMOC (18). We thus turn our attention to ocean circulation changes. Density in the deep Labrador Sea (i.e. averaged between $1000-2500 \mathrm{~m}$ over $60-35^{\circ} \mathrm{W}, 50-65^{\circ} \mathrm{N}$; see box on figure $1 \mathrm{a}$ ) has previously been postulated to be an important proxy of ocean circulation changes and northward heat transport in the North Atlantic $(9 ; 19)$. In the late 1980s to mid 1990s density anomalies in the deep Labrador Sea increased significantly (figure $1 \mathrm{~g}$ ) consistent with the anomalously strong local surface flux forcing by the persistent positive NAO trend (7). The peak in density anomalies led the rapid warming of the upper ocean in the SPG after 1995, consistent with an important influence of the deep Labrador Sea density on the ocean circulation $(1 ; 5 ; 7 ; 9 ; 7 ; 19)$.

Following the peak in the mid 1990s the deep Labrador Sea density index has decreased 
dramatically (see figure $1 \mathrm{~g}$ and (9)). Subsequently, beginning in 2005, the upper ocean temperature in the Eastern North Atlantic $\left(50-10^{\circ} \mathrm{W}, 35-65^{\circ} \mathrm{N}\right.$; shown by the box on fig. $1 \mathrm{e}$ ) cooled significantly (see figure $1 \mathrm{~g}$ ). The change in $0-700 \mathrm{~m}$ heat content over 2005-2014 (assuming a linear trend) is equivalent to an average cooling of $\sim 0.45^{\circ} \mathrm{C}$ or a total cooling of $\sim-1.5 \times 10^{22} \mathrm{~J}$. Such a cooling is equivalent to a sustained surface flux cooling of $\sim-4.5 \mathrm{Wm}^{-2}$ for a decade or sustained heat-budget deficit of $\sim 0.05 \mathrm{PW}$ (for context, this corresponds to a sustained $\sim 0.7 \mathrm{~Sv}\left(1 \mathrm{~Sv}=10^{6} \mathrm{~m}^{3} \mathrm{~s}^{-1}\right)$ weakening of the AMOC at $26.5 \mathrm{~N}$ for a decade (20))

To further investigate the role of ocean circulation in explaining the recent trends, we examine the relationship between the upper ocean state and the index of deep Labrador Sea density in a state-of-the-art model, HadGEM3-GC2, which is able to capture similar events to that observed (see fig $3 \mathrm{~d}$ ). Figure 3 shows that, in the model, a cooling and freshening of the North Atlantic SPG follows a reduction in the deep Labrador Sea density. The cooling and freshening is especially strong in the eastern SPG (ESPG, 38$10^{\circ} \mathrm{W}, 50-62.5^{\circ} \mathrm{N}$; see box on figure $3 \mathrm{~b}$ ), and is also present in SSTs. Along the North American coast and in the Gulf Stream Extension a warming and salinification is also seen, similar to the observed 2005-2014 trend (fig 1 e). These changes in upper ocean heat content are associated with a decrease in the AMOC that occurs approximately simultaneously with the decrease in deep Labrador Sea density anomalies in this model (see figure $3 \mathrm{e}$ ), which is consistent with other high-resolution models (13). The evolution of upper ocean heat content anomalies is consistent with (but opposite sign to) the impact of increased ocean circulation and associated heat transport following an increase in deep Labrador Sea density seen in previous studies $(10 ; 13)$.

The relationships simulated in the model are summarized in figure $3 \mathrm{e}$, which shows the cross-correlation of moving 15-year trends in deep Labrador Sea density with moving 15-year trends of other key variables. 5-10 years before the maximum reduction in the Labrador Sea density there is a warming trend in the ESPG, and a trend to more negative NAO. The warming of the ESPG is followed, by a few years, by warming in the upper (i.e. 0-700m) Labrador Sea, consistent with ocean advection and NAO-related local surface fluxes both playing a role $(21 ; 22)$. The upper ocean $(0-700 \mathrm{~m})$ in the Labrador Sea leads the deeper ocean (i.e. 1000-2500m) by a few years, consistent with lighter waters 
in the upper Labrador Sea, and a reduction in deep convection (13; 22). A reduction in deep Labrador Sea density is then associated with a simultaneous weakening of the AMOC, which precedes a cooling and freshening of the ESPG by 5-10 years. Note that the cooling of the ESPG in the model is also associated with a strengthening of the NAO index towards more positive values, which peaks at lag 5. This trend in the NAO could act to amplify the cooling of the ESPG through increased turbulent heat loss $(21 ; 22)$ but does not dominate the cooling of the ESPG in the model (see supplementary figure S6).

Although there is broad agreement between the model and observations, not surprisingly there are some differences. The observed trends are comparable with the largest trends found in the model. Thus, some of the difference between figures 1 and 3 could be due to comparing a composite of 9 events with a single extreme event (see figures S4 and S5). However, there is also uncertainty in the relationship between deep Labrador Sea density and ocean circulation. For example, the strength of the link between the overturning circulation at subpolar and subtropical latitudes (23), the role of spatial shifts in surface currents in the observed ocean heat-content trends $(18 ; 24)$, and the relative roles of wind stress curl and buoyancy forcing for driving ocean circulation change $(1 ; 25)$ are still not fully understood. Thus, further in-depth observational and model analyses, and advances, will be needed to tease apart the important processes.

In this paper we have shown that a large volume of the North Atlantic has cooled significantly since 2005, reversing the large warming seen in this region since 1990. Several lines of evidence suggest that the explanation for this reversal lies in significant changes in ocean circulation and associated transports. First, the magnitude and spatial pattern of the observed ocean changes cannot readily be explained as a local response to anomalous surface heat fluxes and Ekman pumping associated with concurrent trends in atmospheric circulation. Secondly, the spatial pattern of observed changes in salinity as well as in temperature - involving cooling and freshening in the North East Atlantic and warming and salinification along the western boundary - are consistent with the expected fingerprint of changes in large scale ocean circulation as found in previous studies $(10 ; 22)$, and further supported by specific analyses of model simulations presented in this study. 
An interesting question is to what extent external forcings may have contributed to shaping the recent trends, and trend reversals in the North Atlantic. The observed cooling is not consistent with a dominant role for surface heat flux changes due to anthropogenic aerosols (12). Anthropogenic aerosol loads have decreased in the North Atlantic region since the 1990s, and would therefore be expected to have induced warming of Atlantic SSTs (26) in contrast to the observed cooling. The evidence we have presented is consistent with decadal variability in the NAO being a major driver of Atlantic Multidecadal Variability $(1 ; 10 ; 22)$ through its important role in driving deep Labrador Sea density (7). However, the attribution of this NAO variability to external or internal factors remains very uncertain (27). It has also been hypothesised recently that Greenland Ice melt may be playing an important role in forcing a slowdown of the AMOC over the 20th Century (28). The decomposition of recent changes in deep Labrador Sea density into temperature and salinity contributions (see SI figure S7) shows - perhaps surprisingly - that, although a deep ocean warming is dominating the low density anomalies in the deep Labrador Sea since 1995, the waters here are not (yet) warmer than in the 1970s. However, the waters are fresher, supporting a small, but important, role for the accumulation of additional freshwater in the North Atlantic SPG $(29 ; 28)$ in generating record low densities in the deep Labrador Sea, and hence a slowdown in AMOC. However, the magnitude of any anthropogenic contribution to this freshening is an open and important question $(29 ; 28)$.

Finally, the deep Labrador Sea density is still anomalously low and has decreased over the past decade (see fig. 1), albeit at a slower rate. Given the lag between the deep Labrador Sea density and the upper ocean (i.e. figure 3) we would expect some further cooling of the North Atlantic to take place in agreement with other studies $(11 ; 16 ; 14)$. If the North Atlantic cools further this would likely favour reduced rainfall in the Sahel region (3) and drier summers in Northern Europe (4), as well as a continued suppression of hurricane numbers (2). Additionally, the ongoing cooling could have important implications for the Interdecadal Pacific Oscillation and possibly global mean temperatures (30). Looking further ahead, the EN4 analyses also suggest that the observed cooling of the upper SPG is associated with a small increase in upper-ocean density (not shown). This increase could be the first stage in the next phase reversal of Atlantic Multidecadal Variability, as suggested by simulated mechanisms of natural internal variability $(10 ; 22)$. Therefore, 
monitoring and predicting the ongoing changes in the Atlantic Ocean, and the links to other regions, remains a key priority.

\section{Methods}

In this study we analyse recent changes in the North Atlantic in observed fields. Ocean temperatures (T) and salinity (S) are taken from the EN4.0.2 data set (31). Sea Surface Temperature (SST) is taken from HadISST (32). Surface pressure (SLP) and surface heat fluxes (SHF) are taken from NCEP reanalysis (33). Ocean potential density is calculated from the seasonal-mean EN4 data and is referenced to $2000 \mathrm{~m}$ (i.e. $\sigma_{2}$ ). The deep Labrador Sea density index is calculated by averaging density over $1000-2500 \mathrm{~m}$ in the Labrador Sea $\left(60-35^{\circ} \mathrm{W}, 50-65^{\circ} \mathrm{N}\right.$, see box in figure $\left.1 \mathrm{a}\right)$. Note that, although the integral (in time) of anomalous surface heat fluxes (SHF) is related to the change in heat content, there remain substantial difficulties with calculating ocean heat budgets with the surface flux products available (34). Therefore, in figure 2 we focus on trends in SHF, which we assume are less sensitive to biases and uncertainties in SHF products. A more rigorous quantification of the role of SHFs is presented in the Supplementary Information.

We also analyse data from the latest coupled climate model from the UK Met Office, HadGEM3 - Global Configuration v2 (HadGEM3-GC2, (35)). This version of HadGEM3 has an atmospheric resolution of $\sim 60 \mathrm{~km}$ in the extra-tropics and a vertical resolution of 85 levels. The ocean model is based on NEMO, and has a resolution of $0.25^{\circ}$ and 75 vertical levels. We use 300 years of annual-mean data taken from a control run (i.e. with no changes to external forcings) to focus on the models internal variability. Model drift is removed through linear detrending at each grid point.

For figure 3 we perform a composite trend analysis based on periods in the model's control simulation which show the largest reductions in deep Labrador Sea density. Specifically, we use a composite of 9 events which were defined by finding the 9 largest independent (i.e. the trends are not allowed to overlap) 15-year trends in $\sigma_{2}$ averaged over the 1000$2500 \mathrm{~m}$ in the Labrador Sea $\left(60-35^{\circ} \mathrm{W}, 50-65^{\circ} \mathrm{N}\right)$. Note that no smoothing is applied to 
the data before trends are calculated, and an example of the variability (i.e. before calculating 15-year trends) in the Labrador Sea density and ocean heat content in the eastern SPG is shown in figure $3 \mathrm{~d}$. We analyse 15-year trends in order to focus on decadal time-scale changes.

Composite spatial trends (i.e. figs. 3 a-c) for SST and upper-ocean (0-700m) temperature and salinity (T700 and S700, respectively) are offset from the trends in Labrador Sea density by a lag of 5 years (which is the lag with the largest significant correlation, see fig 3 e) in order to highlight changes that follow decreases in Labrador Sea density. The North Atlantic Oscillation (NAO) index used in figure 3 e is calculated based on a pressure difference between Iceland and the Azores (17). The AMOC index is defined at the depth of maximum overturning from the climatological stream-function $(\sim 1100 \mathrm{~m})$. Not the Ekman variability is removed from the AMOC index (36) in order to focus on the geostrophic AMOC variability of the model. Note that figure $3 \mathrm{e}$ is not sensitive to the use of rolling 15-year trends; the results are similar when calculating the cross-correlation with rolling 10-year trends or low-pass filtered time-series (i.e. where time-periods between 10-60 years are retained).

Finally, to find if the trends in figure 3 are significantly different to zero, we perform a Monte Carlo significance test. Specifically, we compare the specific average of 9 15year trends computed for figure 3 to a distribution representing all possible averages of the 9 15-year trends available from the control run. We compute this distribution at each grid-point by meaning 9 independent 15-year trends which are drawn at random, a total of 1000 times. The significance test applied to the observations in figure 1 and figure 2 simply shows where the magnitude of the linear trend is larger than two times the standard error of the residuals (i.e. the difference between the linear-trend and original time-series. These 'residuals' represent the variance not explained by the linear trend over the time period for which the trend is fitted.), assuming that the residuals are independent. 


\section{Data Sources}

EN4 and HadISST data are provided by the UK Met Office (http://www.metoffice.gov.uk/hadobs/).

NCEP reanalysis is provided by the USA National Oceanographic and Atmospheric Administration's (NOAA) Earth System Research Laboratory (http://www.esrl.noaa.gov). ERA-interim data is provided by the European Centre for Medium-Range Weather Forecasts (http://www.ecmwf.int/en/research/climate-reanalysis/era-interim). Finally, the climate model data for HadGEM3-GC2 was provided to us by the UK Met Office.

\section{Code availability}

The code and scripts used to analyse the data are based on widely available tools, including IDL, Ferret (available from NOAA, http://www.ferret.noaa.gov/Ferret/) and the Climate Data Operators (available from the Max-Planck Institute for Meteorology, https://code.zmaw.de/projects/cdo). Specific codes can be requested from the corresponding author.

\section{References}

[1] Robson, J., Sutton, R., Lohmann, K., Smith, D. \& Palmer, M. Causes of the Rapid Warming of the North Atlantic ocean in the mid 1990s. J Clim. 25, 4116-4134 (2012).

[2] Smith, D. M. et al. Skilful multi-year predictions of Atlantic Hurricane frequency. Nature geoscience 3, 846-849 (2010).

[3] Zhang, R. \& Delworth, T. Impact of Atlantic multidecadal oscillations on india/sahel rainfall and Atlantic hurricanes. Geophys. Res. Lett 33 (2006).

[4] Sutton, R. T. \& Dong, B. Atlantic Ocean influence on a shift in European climate in the 1990s. Nature Geoscience 5, 788-792 (2012).

[5] Yeager, S., Karspeck, A., Danabasoglu, G., Tribbia, J. \& Teng, H. A Decadal Pre- 
diction Case Study: Late Twentieth-Century North Atlantic Ocean Heat Content. Journal of Climate 25, 5173-5189 (2012).

[6] Robson, J. I., Sutton, R. T. \& Smith, D. M. Initialized predictions of the rapid warming of the North Atlantic Ocean in the mid 1990s. Geophys. Res. Lett 25, L19713 (2012).

[7] Yeager, S. \& Danabasoglu, G. The origins of late-twentieth-century variations in the large-scale North Atlantic circulation. Journal of Climate 27, 3222-3247 (2014).

[8] Smeed, D. et al. Observed decline of the Atlantic Meridional Overturning Circulation 2004 to 2012. Ocean Science Discussions 10, 1619-1645 (2013).

[9] Robson, J., Hodson, D., Hawkins, E. \& Sutton, R. Atlantic overturning in decline? Nature Geoscience 7, 2-3 (2014).

[10] Dong, B. \& Sutton, R. T. Mechanism of Interdecadal Thermohaline Circulation Variability in a Coupled Ocean-Atmosphere GCM. Journal of Climate 18, 1117$1135(2005)$.

[11] Hermanson, L. et al. Forecast cooling of the Atlantic subpolar gyre and associated impacts. Geophysical research letters 41, 5167-5174 (2014).

[12] Booth, B., Dunstone, N., Halloran, P., Andrews, T. \& Bellouin, N. Aerosols implicated as a prime driver of twentieth-century North Atlantic climate variability. Nature 484, 228-232 (2012).

[13] Hodson, D. L. \& Sutton, R. T. The impact of resolution on the adjustment and decadal variability of the Atlantic meridional overturning circulation in a coupled climate model. Climate Dynamics 39, 3057-3073 (2012). URL http://dx.doi.org/10.1007/s00382-012-1309-0.

[14] McCarthy, G. D., Haigh, I. D., Hirschi, J. J.-M., Grist, J. P. \& Smeed, D. A. Ocean impact on decadal Atlantic climate variability revealed by sea-level observations. Nature 521, 508-510 (2015).

[15] Clement, A. et al. The Atlantic Multidecadal Oscillation without a role for ocean circulation. Science 350, 320-324 (2015). 
[16] Kloewer, M., Latif, M., Ding, H., Greatbatch, R. J. \& Park, W. Atlantic meridional overturning circulation and the prediction of North Atlantic sea surface temperature. Earth and Planetary Science Letters 406, 1-6 (2014).

[17] Hurrell, J. W. Decadal Trends in the North Atlantic Oscillation: Regional Temperatures and Precipitation. Science 269, 676-679 (1995).

[18] Zhang, R. \& Vallis, G. The role of bottom vortex stretching on the path of the North Atlantic western boundary current and on the northern recirculation gyre. Journal of Physical Oceanography 37, 2053-2080 (2007).

[19] Roberts, C. D., Garry, F. K. \& Jackson, L. C. A Multimodel Study of Sea Surface Temperature and Subsurface Density Fingerprints of the Atlantic Meridional Overturning Circulation. Journal of Climate 26, 9155-9174 (2013).

[20] Johns, W. et al. Continuous, Array-Based Estimates of Atlantic Ocean Heat Transport at 26.5 n. Journal of Climate 24, 2429-2449 (2011).

[21] Visbeck, M. et al. The ocean's response to North Atlantic Oscillation variability. In The North Atlantic Oscillation: Cinematic Significance and Environmental Impact, 113-146 (Amer. Geophys. Union, 2003).

[22] Menary, M. B., Hodson, D. L., Robson, J. I., Sutton, R. T. \& Wood, R. A. A Mechanism of Internal Decadal Atlantic Ocean Variability in a High-Resolution Coupled Climate Model. Journal of Climate 28, 7764-7785 (2015).

[23] Lozier, M. S., Roussenov, V., Reed, M. S. \& Williams, R. G. Opposing decadal changes for the North Atlantic meridional overturning circulation. Nature Geoscience 3, 728-734 (2010).

[24] Hátún, H., Sandø, A. B., Drange, H., Hansen, B. \& Valdimarsson, H. Influence of the Atlantic Subpolar Gyre on the Thermohaline Circulation. Science 309, 1841-1844 (2005).

[25] Barrier, N., Cassou, C., Deshayes, J. \& Treguier, A.-M. Response of North Atlantic Ocean Circulation to Atmospheric Weather Regimes. Journal of Physical Oceanography 44, 179-201 (2014). 
[26] Gettelman, A., Shindell, D. \& Lamarque, J. Impact of aerosol radiative effects on 2000-2010 surface temperatures. Climate Dynamics 2165-2179 (2015).

[27] Pinto, J. G. \& Raible, C. C. Past and recent changes in the North Atlantic oscillation. Wiley Interdisciplinary Reviews: Climate Change 3, 79-90 (2012).

[28] Rahmstorf, S. et al. Exceptional twentieth-century slowdown in Atlantic Ocean overturning circulation. Nature Climate Change 5, 475-480 (2015).

[29] Curry, R. \& Mauritzen, C. Dilution of the Northern North Atlantic Ocean in Recent Decades. Science 308, 1772-1774 (2005).

[30] McGregor, S. et al. Recent walker circulation strengthening and Pacific cooling amplified by Atlantic warming. Nature Climate Change 4, 888-892 (2014).

[31] Good, S. A., Martin, M. J. \& Rayner, N. A. En4: Quality controlled ocean temperature and salinity profiles and monthly objective analyses with uncertainty estimates. Journal of Geophysical Research: Oceans 118, 6704-6716 (2013).

[32] Rayner, N. et al. Global analyses of sea surface temperature, sea ice, and night marine air temperature since the late nineteenth century. Journal of Geophysical Research-Atmospheres 108, 4407 (2003).

[33] Kalnay, E. et al. The NCEP/NCAR 40-year reanalysis project. Bulletin of the American Meteorological Society 77, 437-471 (1996).

[34] Josey, S., Gulev, S. \& Yu, L. Exchanges through the ocean surface. In Sidler, G., Griffies, S., Gould, J. \& Church, J. (eds.) Ocean Circulation and Climate: A 21st Century Perspective (Academic Press, 2013).

[35] Williams, K. et al. The Met Office Global Coupled model 2.0 (GC2) configuration. Geoscientific Model Development Discussions 8, 521-565 (2015).

[36] Baehr, J., Hirschi, J., Beismann, J. \& Marotzke, J. Monitoring the meridional overturning circulation in the North Atlantic: A model-based array design study. Journal of Marine Research 62, 283-312 (2004). 


\section{${ }_{340} 4$ Corresponding author}

${ }_{322} 5$ Acknowledgements

We thank the UK Met Office, and particularly Martin Andrews, for providing the model data used in this study. J.R. was supported by the Seasonal-to-Decadal Climate Prediction for the Improvement of European Climate Service project (SPECS, GA 308378) and J.R. and P.O were supported by the Dynamics and Predictability of the Atlantic Meridional Overturning and Climate project (DYNAMOC, NE/M005127/1). R.S. was supported by NERC via the National Centre for Atmospheric Science (NCAS).

\section{Author contributions}

J.R. and R.S. jointly conceived the study. J.R. and P.O. analysed the observational and model data. J.R. led the writing of the manuscript with contributions and input from all authors. 
Figure 1: Recent upper ocean trends in the North Atlantic. a) shows the linear trend in SST calculated over 1990-2004 $\left[{ }^{\circ} \mathrm{C} /\right.$ Decade] from HadISST. The stippling shows where the fitted trend is larger than $2 \sigma$ error in the residuals (see methods). b) and c) show the same as a) but now for 0-700m temperature and salinity (T700 [ ${ }^{\circ} \mathrm{C} /$ Decade] and S700 [PSU/Decade] respectively) as calculated from the EN4 data set. d)-f) the same as a)-c) but now for the 2005-2014 period. g) shows the time-series of T700 and S700 $\times 10$ averaged over the Eastern North Atlantic $\left(50-10^{\circ} \mathrm{W}, 35-65^{\circ} \mathrm{N}\right.$, which is shown on panel e); black and blue respectively), and the deep Labrador Sea density (DLS density, red) which is the $1000-2500 \mathrm{~m}$ average density $\left(\sigma_{2}\right)$ in the Labrador Sea $\left(60-35^{\circ} \mathrm{W}, 50-65^{\circ} \mathrm{N}\right.$, which is shown on panel a)). Anomalies in g) are made relative to 1961-1990.

Figure 2: The role of the atmosphere in recent changes in the North Atlantic. a) shows the linear trend in SLP calculated over 1990-2004 [hPa/Decade], from NCEP reanalysis. The stippling shows where the fitted trend is larger than 2 standard deviations of the residual errors (see methods). b) and c) show the same as a) but now for wind stress curl and annual-mean net surface fluxes (WSC $\left[10^{-7} \mathrm{~N} \mathrm{~m}^{-3} /\right.$ decade $]$ and SHF $\left[\mathrm{W} \mathrm{m}^{-2} /\right.$ decade] respectively) as calculated from the NCEP reanalysis data set. Note that positive windstress curl anomalies in b) represents increased Ekman upwelling, and positive SHF anomalies in c) represents a warming of the ocean. d)-f) the same as a)-c) but now for the 2005-2014 period. 
Figure 3: Simulated ocean trends following a reduction in deep Labrador Sea density. a) shows the a composite of 15-year linear-trends in SST following the 9 strongest trends in Labrador Sea Density $\left[{ }^{\circ} \mathrm{C} /\right.$ Decade] where SST trends are offset by 5 years (i.e. the first year used to compute the SST trend lags the first year used to calculate the deep Labrador Sea density index by 5 years). Stippling shows where trends are significant at the $\mathrm{p} \leq 0.1$, see methods for details. b) and c) show the same as a) but now for $0-700 \mathrm{~m}$ average temperature anomaly $\left(\mathrm{T} 700\left[{ }^{\circ} \mathrm{C} /\right.\right.$ Decade $\left.]\right)$ and $0-700 \mathrm{~m}$ average salinity anomaly S700 [PSU/Decade]). d) shows the standardized time-series of deep Labrador Sea density (DLS density, green), and the Eastern SPG $\left[\sim 38-10^{\circ} \mathrm{W}, 50-62.5^{\circ} \mathrm{N}\right.$; see box on $\left.3 \mathrm{~b}\right] 0-$ $700 \mathrm{~m}$ temperature (ESPG T700) anomaly for a portion of the simulation. e) shows the lead/lag relationship between rolling 15-year trends in deep Labrador Sea (DLS) density, and the 15 -year trends in AMOC at $40^{\circ} \mathrm{N}$ (with Ekman component removed see methods, magenta), NAO index (red), Labrador Sea 0-700m temperature (LS T700, green), and the Eastern SPG (ESPG, blue) for 0-700m temperature (T700, solid) and 0-700m salinity (S700, dash). Positive lags show where the deep Labrador Sea density is leading the other variables. Note that for e) the Labrador Sea density anomalies are multiplied by -1 to show how the metrics evolve before and after a negative trend in deep Labrador Sea density. 
a) SST $1990-2004$

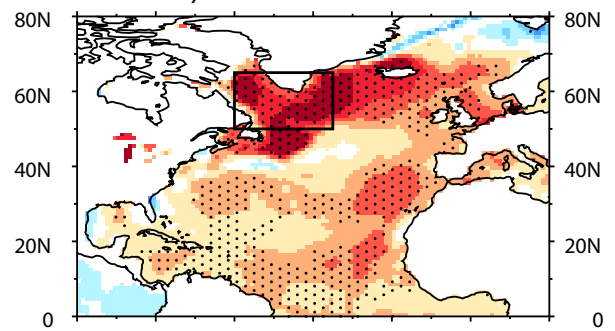

100W 80W 60W 40W 20W 0 W 20E

$\begin{array}{lllll}-0.9 & -0.5 & -0.1 & 0.3 & 0.7\end{array}$

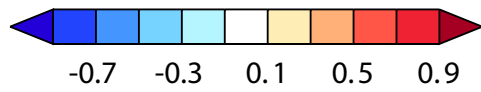

d) SST 2005-2014
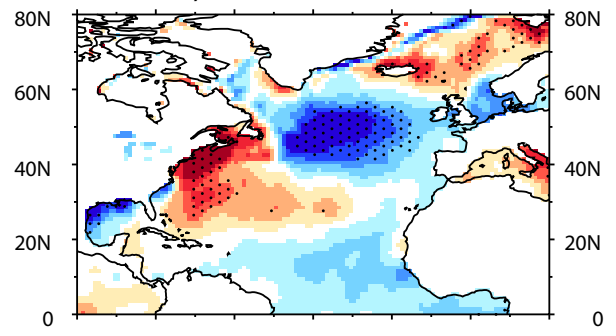

100W 80W 60W 40W 20W 0 20E 100W

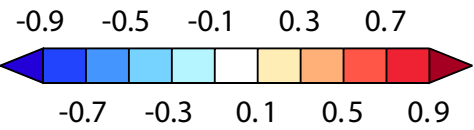

b) T700 1990-2004
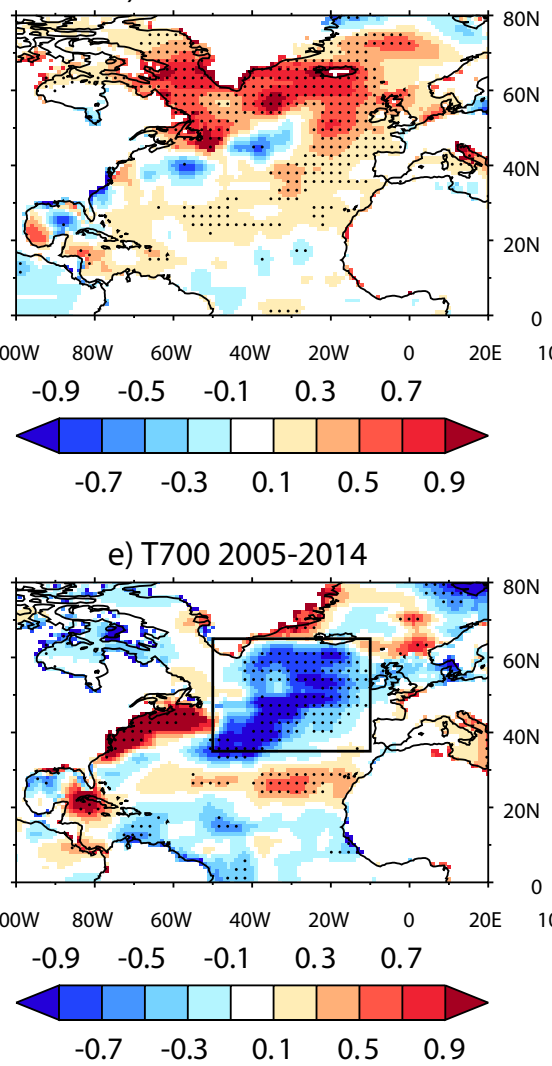

c) 5700 1990-2004

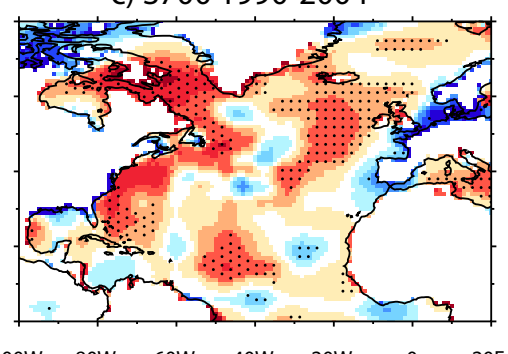

$\begin{array}{lllll}-0.2 & -0.05 & -0.01 & 0.03 & 0.1\end{array}$

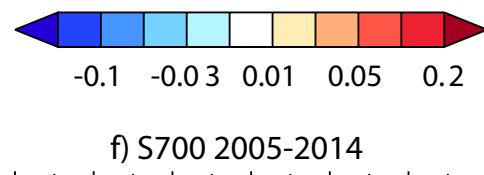

g) North East Atlantic mean (50-10 $\left.{ }^{\circ} \mathrm{W} ; 35-65^{\circ} \mathrm{N}\right)$

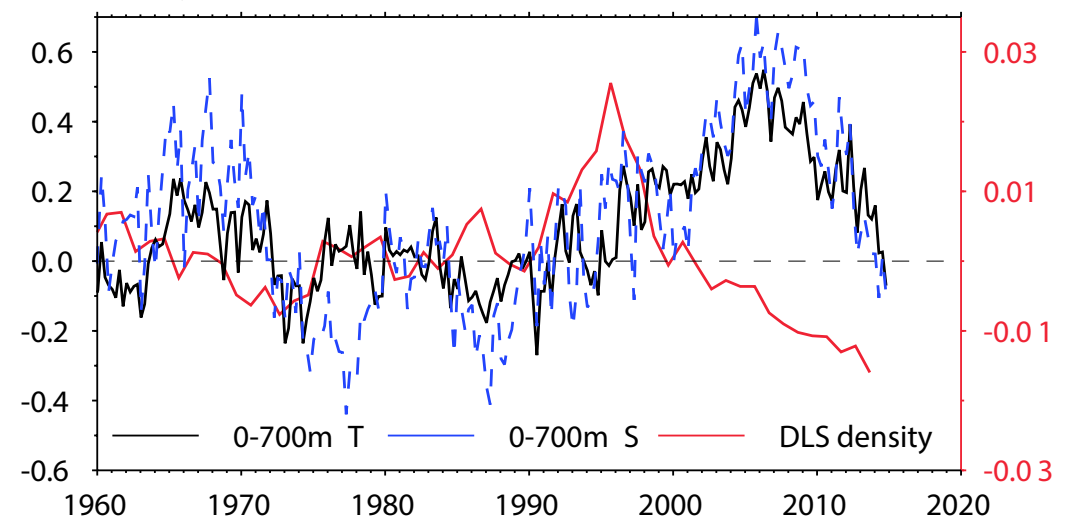


a) SST Trend (K/decade)
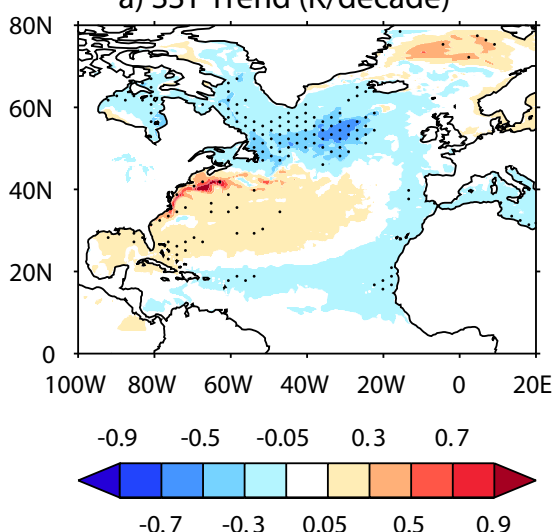

d) Local Averages

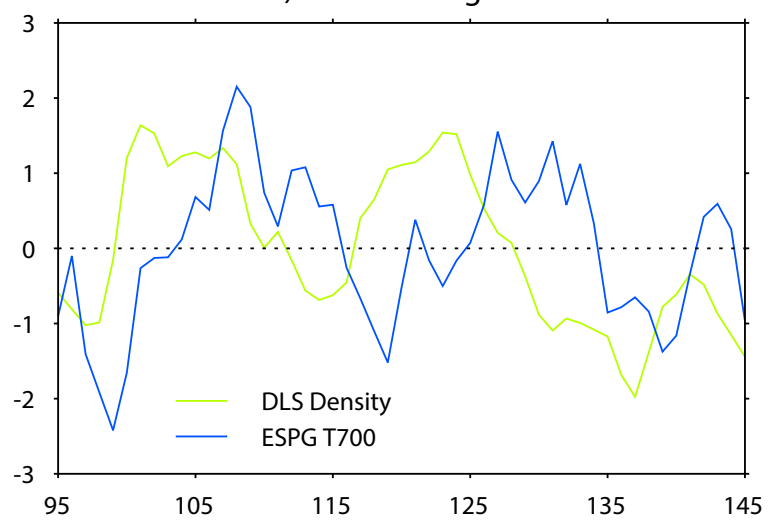

e) Correlations vs D1000-2500 Labrador Trends

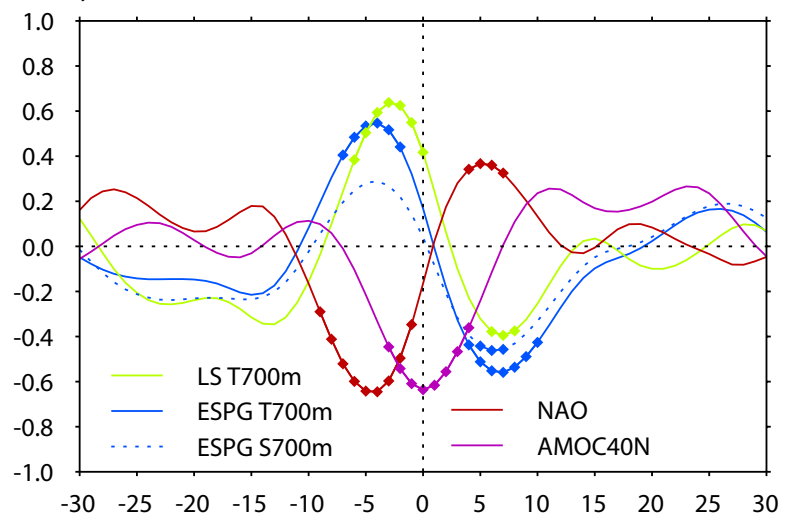

